\title{
Simplified Finite Set Model Predictive Control Strategy of Grid-Connected Cascade H-Bridge Converter
}

\author{
Jingang Han, ${ }^{1}$ Chao Li, ${ }^{1}$ Tengfei Yang, ${ }^{1}$ and Jun Han ${ }^{2}$ \\ ${ }^{1}$ Department of Electrical Automation, Shanghai Maritime University, Shanghai 201306, China \\ ${ }^{2}$ Economic Research Institute, State Grid Jiangsu Electric Power Company, Nanjing 210000, China \\ Correspondence should be addressed to Jingang Han; jghan@shmtu.edu.cn
}

Received 2 February 2016; Revised 21 April 2016; Accepted 8 May 2016

Academic Editor: Michela Robba

Copyright (c) 2016 Jingang Han et al. This is an open access article distributed under the Creative Commons Attribution License, which permits unrestricted use, distribution, and reproduction in any medium, provided the original work is properly cited.

Finite set model predictive control (FS-MPC) has become a promising control technology in power converter, because of the advantages of good dynamic response and accurate current tracking capability. In real-time control process, the conventional FSMPC strategy requires more time for prediction and optimization. As a result, there will be a certain delay between sampling and output. In order to reduce the amount of calculation and overcome the adverse effect of the delay on the system performance, this paper presents a simplified FS-MPC method. Firstly, adjacent levels method is used to reduce the amount of the calculation, and then two-step FS-MPC is adopted to compensate the calculation delay. The control strategy is validated by the simulation and experimental results of a grid-connected cascaded $\mathrm{H}$-bridge converter.

\section{Introduction}

The ever-increasing fossil fuel energy consumption, exhaustible nature, and worsening global environment have created a booming interest in large-scale renewable energy utilization systems. As the grid-connected inverter is one of the necessary pieces of equipment of the renewable energy application, its performance is very important for using the renewable energy effectively and safely. In order to get a highperformance large-scale renewable energy application system, the study of the multilevel inverters is needed. The advantages of these inverters are small $d v / d t$ and EMI, low switching frequency, high inverting efficiency, and suitability for high-power applications [1-3]. The most dominant topologies of multilevel converters are the neutral point clamped (NPC) [4], flying capacitor (FC) [5], and the cascaded H-bridge (CHB) converter [6]. This paper focuses on the three-phase cascaded H-bridge inverter.

Current control techniques of inverters can be classified into two main groups: linear and nonlinear techniques. Due to the fact that microprocessor computing power has been greatly improved, the nonlinear current control techniques have been paid more attention. The nonlinear current control techniques include hysteresis control, deadbeat control, and finite set model predictive control (FS-MPC) [7-9]. The advantages of the FS-MPC are clear and simple control, good dynamic performance, strong current tracking ability, and good adaptability to different variables [10-12]. FS-MPC will predict the future behavior of the variables in time frame according to the model of the system. Then, all the predictions are evaluated using the cost function and the state that minimizes the cost function is chosen as the optimal state.

FS-MPC has become a promising control technique in power converter and $\mathrm{AC}$ motor drives. In multilevel inverters, FS-MPC has been applied for a three-level NPC inverter [13], a flying capacitor inverter [14], an asymmetric CHB inverter [15], and a hybrid asymmetric multilevel inverter [16]. However, most of the switching states or all of the switching states are used to find the optimal state in those papers. So there is a large amount of calculation. As a result, there will be a certain delay which causes adverse effect to the system performance between sampling and output. 


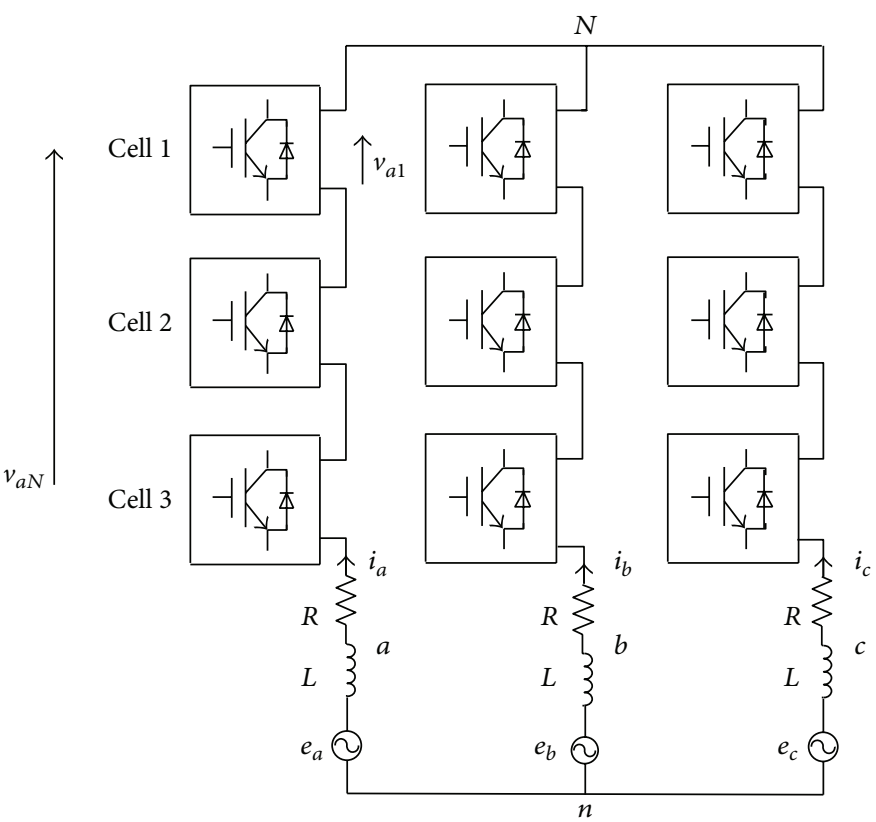

(a)

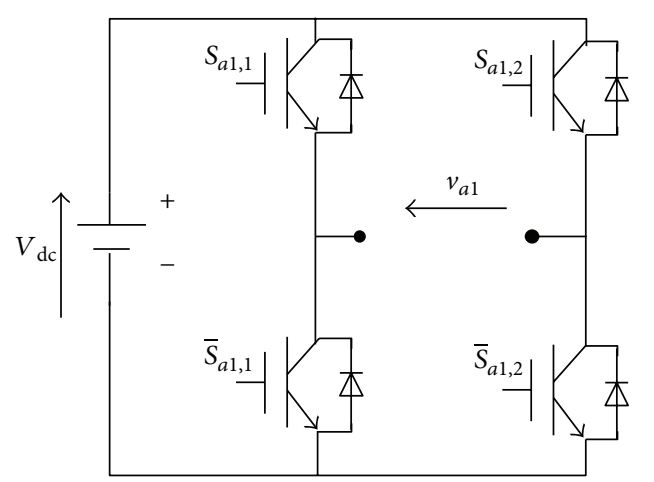

(b)

FIgURE 1: CHB inverter. (a) Three-cell CHB three-phase grid-connected inverter. (b) Topology of one cell.

In order to reduce the amount of calculation and overcome the adverse effect of the delay on the system performance, this paper presents a simplified FS-MPC method. This method is realized by selecting the adjacent levels and adopting two-step FS-MPC method. A seven-level gridconnected cascaded $\mathrm{H}$-bridge inverter is used for simulation and experimental analysis.

\section{System Model}

The three-phase cascaded H-bridge inverter is shown in Figure 1(a). Every phase of CHB inverter consists of three $\mathrm{H}$ bridge cells. Each cell can generate an output voltage of $-V_{\mathrm{dc}}$, $0,+V_{\mathrm{dc}}$ with a dc-link voltage $V_{\mathrm{dc}}$, as shown in Figure 1(b). The number of possible voltage levels $L$ of each phase is

$$
L=2 C+1
$$

where $C$ is the number of cells in each phase. For a threephase inverter, the number of voltage level vectors $K_{L}$ is

$$
K_{L}=L^{3}
$$

Each cell has two switching signals, and for $C$ cells in one phase, the voltage of the inverter in terms of binary switching signals is

$$
V_{i N}=V_{\mathrm{dc}} \sum_{i=0}^{C}\left(S_{i j, 1}-S_{i j, 2}\right) \quad i=a, b, c,
$$

where $S_{i j, 1}$ and $S_{i j, 2}$ are the binary switching signals of the cell $j$. The possible switching combination $K_{S}$ for a CHB inverter with $C$ cells in one phase is $K_{S}=2^{2 C}$. For three-phase inverter, the possible switching combination is

$$
K_{S}=2^{6 C}
$$

As an example, in a three-phase $\mathrm{CHB}$ inverter with three cells, as shown in Figure 1(a), it is possible to generate $L=7$ voltage levels in each phase and there are $2^{18}$ switching combinations. For one of the voltage levels, it may have different combinations of output voltage of each cell. Single-phase 3cell $\mathrm{CHB}$ inverter has 64 possible switching combinations; most of them are redundant. If all the switching combinations are considered, there will be a great amount of computation.

According to Figure 1(a), the differential equation of the grid-connected current for a single-phase CHB gridconnected inverter is

$$
L \frac{d i_{a}}{d t}+R i_{a}+e_{a}=v_{a}
$$

where $v_{a}$ is the output voltage of the single-phase CHB gridconnected inverter.

\section{Finite Set Model Predictive Control}

3.1. Discrete Model and Prediction. The main idea of the predictive current control scheme used in this paper is to predict the behavior of the grid-connected current for each possible voltage level generated by the inverter. A discretetime form of the differential equation of the grid-connected current (5) for a sampling time $T_{\mathrm{s}}$ can be used to predict the future value of grid-connected current with the measured current and grid voltage at the sample $k$. 


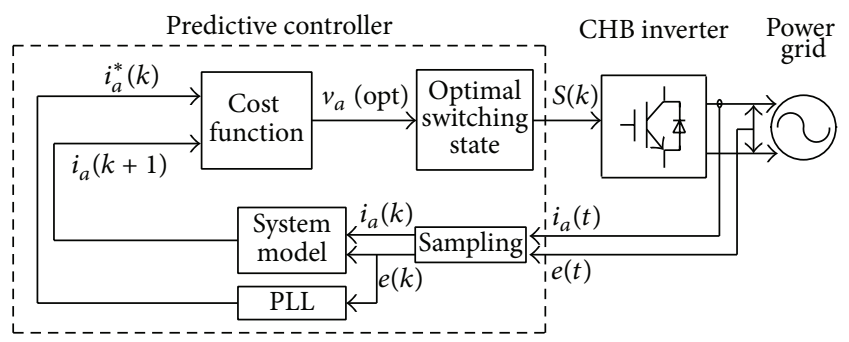

FIGURE 2: Block diagram of the FS-MPC algorithm.

Approximating the derivative $d i_{a} / d t$ in (5) by

$$
\frac{d i_{a}}{d t} \approx \frac{i_{a}[k+1]-i_{a}[k]}{T_{\mathrm{s}}}
$$

and placing it in (5), the following expression is obtained for the future load current:

$$
i_{a}(k+1)=\left(1-\frac{R T_{s}}{L}\right) i_{a}(k)+\frac{T_{s}}{L}\left(v_{a}(k)-e_{a}(k)\right) .
$$

This equation will be used in the controller to predict the future grid-connected current for a given voltage level.

3.2. Cost Function. Equation (7) is used to predict the behavior of the output current for each one of all the voltage levels. Each prediction is evaluated using a cost function. Voltage level that minimizes the cost function is selected, and the switching state of voltage level is applied during a whole sampling period.

The control objective of the grid-connected inverter is to make the error between grid-connected current and the reference current minimum, and the cost function in this paper is selected:

$$
g=\left|i_{a}^{*}(k+1)-i_{a}(k+1)\right|,
$$

where $i_{a}^{*}(k+1)$ is the reference current at the sample $k$ and $i_{a}(k+1)$ is the prediction current at the sample $k$. For sufficiently small sampling times, it can be assumed that $i_{a}^{*}(k+1) \approx i_{a}^{*}(k)$. For larger sample times, derivation of the reference is needed [13].

Equation (8) is used to calculate the error of the predicted current and reference current for each possible voltage level. The voltage level which minimizes the cost function is selected and applied to the load.

3.3. Finite Set Model Predictive Control. The main idea of the FS-MPC scheme is to predict the behavior of the controlled variables according to the discrete-time model of the controlled variables. The model predictive current control scheme is shown in Figure 2, and it consists of the following steps [17]:

(1) Measure the grid-connected current and grid voltage value.
TABLE 1: Switching states.

\begin{tabular}{lccccccccc}
\hline Output voltage & \multicolumn{4}{c}{ Cell voltage } & \multicolumn{4}{c}{ Switching states } \\
$V_{o}$ & $V_{1}$ & $V_{2}$ & $V_{3}$ & $S_{1,1}$ & $S_{1,2}$ & $S_{2,1}$ & $S_{2,2}$ & $S_{3,1}$ & $S_{3,2}$ \\
\hline$-3 V_{\mathrm{dc}}$ & $-V_{\mathrm{dc}}$ & $-V_{\mathrm{dc}}$ & $-V_{\mathrm{dc}}$ & 0 & 1 & 0 & 1 & 0 & 1 \\
$-2 V_{\mathrm{dc}}$ & 0 & $-V_{\mathrm{dc}}$ & $-V_{\mathrm{dc}}$ & 0 & 0 & 0 & 1 & 0 & 1 \\
$-V_{\mathrm{dc}}$ & 0 & 0 & $-V_{\mathrm{dc}}$ & 0 & 0 & 0 & 0 & 0 & 1 \\
0 & 0 & 0 & 0 & 0 & 0 & 0 & 0 & 0 & 0 \\
$V_{\mathrm{dc}}$ & 0 & 0 & $-V_{\mathrm{dc}}$ & 0 & 0 & 0 & 0 & 1 & 0 \\
$2 V_{\mathrm{dc}}$ & 0 & $-V_{\mathrm{dc}}$ & $-V_{\mathrm{dc}}$ & 0 & 0 & 1 & 0 & 1 & 0 \\
$3 V_{\mathrm{dc}}$ & $-V_{\mathrm{dc}}$ & $-V_{\mathrm{dc}}$ & $-V_{\mathrm{dc}}$ & 1 & 0 & 1 & 0 & 1 & 0 \\
\hline
\end{tabular}

(2) Obtain the reference current value of the same frequency and phase with the grid voltage through the PLL phase-locked loop.

(3) Predict all possible grid-connected current values of the time $k+1$ according to (7).

(4) According to the cost function of (8) to evaluate all of the predicted current value of the time $k+2$ and select the one that minimizes the cost function as the optimal value, the switch state corresponding to the optimal value is the optimal switch state.

(5) Wait until sampling time $k+1$ and turn back to step (1).

\section{Simplified Finite Set Model Predictive Control}

Ideally, the sampling, prediction, evaluation, and output are completed at the same moment, but actually, there is a certain delay between sampling and the output. The delay will affect the performance of the grid-connected inverter. For example, for a three-phase CHB inverter with three cells as shown in Figure 1(a), according to (2) and (4), there are $7^{3}$ voltage vectors and $2^{18}$ switching combinations. If all the voltage vectors and switching states are considered to find the optimal state, there will be a great amount of computation. As a result, there will be a great time delay. In this paper, the grid-connected current prediction of each phase is calculated separately. Each phase has 64 switching states corresponding to 7 voltage levels. Removing the redundant switching states, switching states table can be got, as shown in Table 1 . Therefore, for a three-phase CHB inverter with three cells, as shown in Figure 1(a), it only needs to calculate 21 times to find the optimal switching states for each sampling time. But the number of output levels will increase with the increase of the cells number. Therefore the amount of calculation will increase. For this reason, this paper presents a simplified FS-MPC method to reduce the amount of calculation and overcome the adverse effect of the delay on the system performance. This method is realized by selecting the adjacent levels and adopting two-step FS-MPC method. The method can be applied to the control of an arbitrary level multilevel inverter.

4.1. Selection of Adjacent Levels. After removing the redundant switching states, the amount of calculation has been 


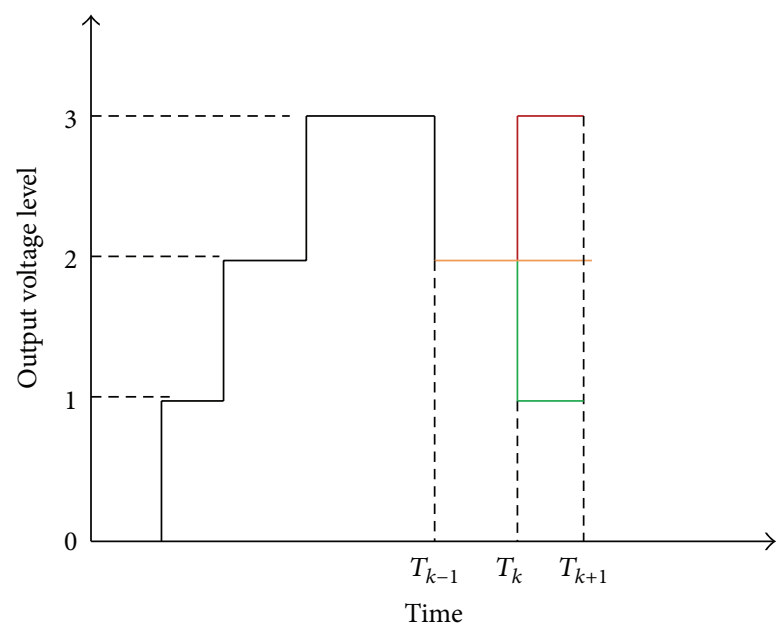

FIgURE 3: FS-MPC of selecting adjacent levels.

reduced. But it will increase with the increase of the cells number. Therefore the method of selecting adjacent levels is used to reduce the amount of the calculation.

The basic principle of selecting adjacent levels FS-MPC is shown in Figure 3 [18]. For sufficiently small sampling times, assuming the optimal output level of the time $k-1$ is level two, then the optimal output level of the time $k$ is level one, level two, and level three. The FS-MPC of load current can be realized by predicting and evaluating the three adjacent levels. As an example, in a three-phase CHB inverter with three cells, as shown in Figure 1(a), it only needs to calculate up to 3 times to find the optimal switching states of each phase for each sampling time. So it only needs to calculate up to 9 times for a three-phase CHB inverter to complete the FSMPC algorithm for each sampling time. The prediction and evaluation times of conventional FS-MPC are proportional to the numbers of the output voltage levels. But the prediction and evaluation times of selecting adjacent levels FS-MPC in each sampling period are independent of the number of the output voltage levels. At the same time, a voltage waveform with smaller $d v / d t$ can be obtained due to the transitions between adjacent levels.

4.2. Two-Step FS-MPC. Although the amount of calculation has been greatly reduced after selecting adjacent levels, there is still a certain delay between sampling and output. Twostep FS-MPC method is used to compensate the calculation delay. Figure 4 shows a block diagram of the two-step FSMPC system. $v_{a}(\mathrm{opt})$ is the optimal output voltage vector of the time $k$, so according to (7), the grid-connected current of the time $k+1$ can be calculated with the following function:

$$
i_{a}(k+1)=\left(1-\frac{R T_{s}}{L}\right) i_{a}(k)+\frac{T_{s}}{L}\left(v_{a}(\mathrm{opt})-e_{a}(k)\right)
$$

After obtaining the grid-connected current of the time $k+$ 1 , all possible grid-connected current of the time $k+2$ can be figured out and the optimal switching state can be selected

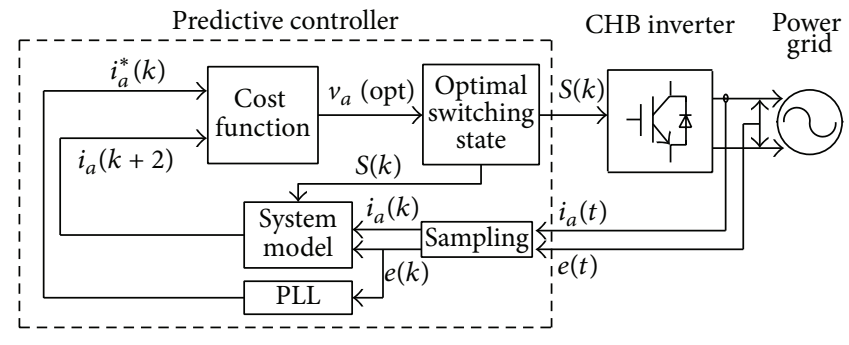

FIGURE 4: Block diagram of the two-step FS-MPC algorithm.

using the cost function. According to (7) and (9), the gridconnected current of the time $k+2$ can be calculated with the following function:

$$
\begin{aligned}
i_{a}(k+2)= & \left(1-\frac{R T_{s}}{L}\right) i_{a}(k+1) \\
& +\frac{T_{s}}{L}\left(v_{a}(k+1)-e_{a}(k+1)\right) .
\end{aligned}
$$

For sufficiently small sampling times, it can be assumed that $e_{a}(k+1) \approx e_{a}(k)$. The control cycle of the two-step FSMPC at sampling time $k(k \geq 0)$ is described step by step as follows [19]:

(1) Update the switching state of the switch tubes according to the optimal switching state that is worked out at sampling time $k-1$.

(2) Measure the grid-connected current and grid voltage value.

(3) Obtain the reference current value of the same frequency and phase with the grid voltage through the PLL phase-locked loop.

(4) According to (9) and the switch state of the present moment $(k)$, calculate the grid-connected current value of the time $k+1$. 


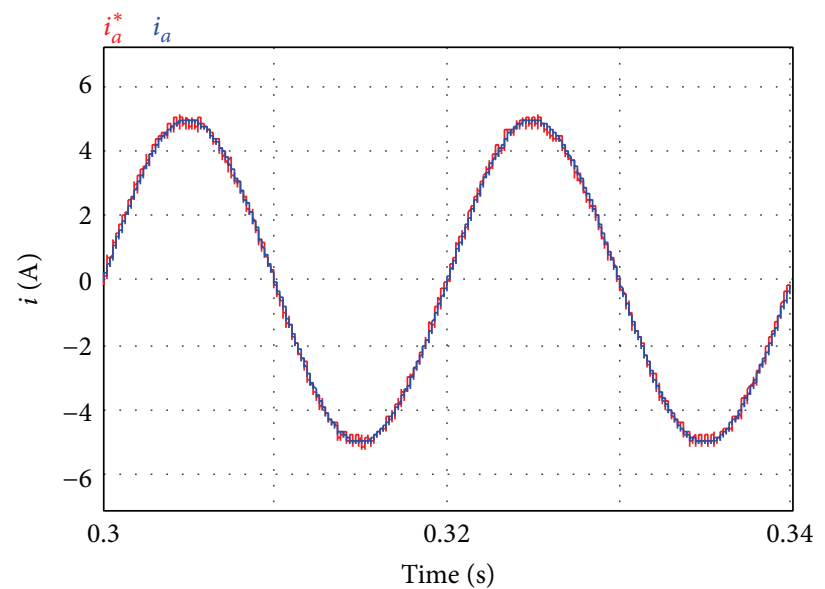

(a)

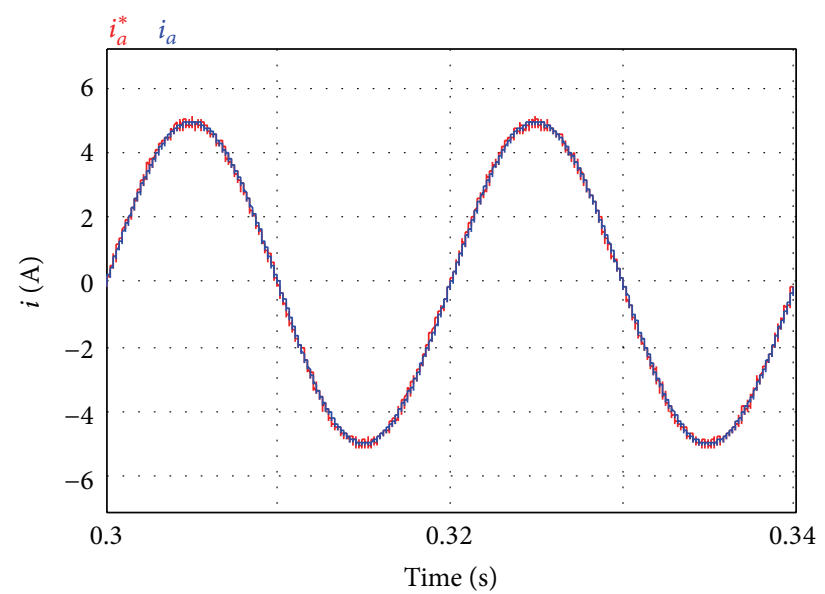

(c)

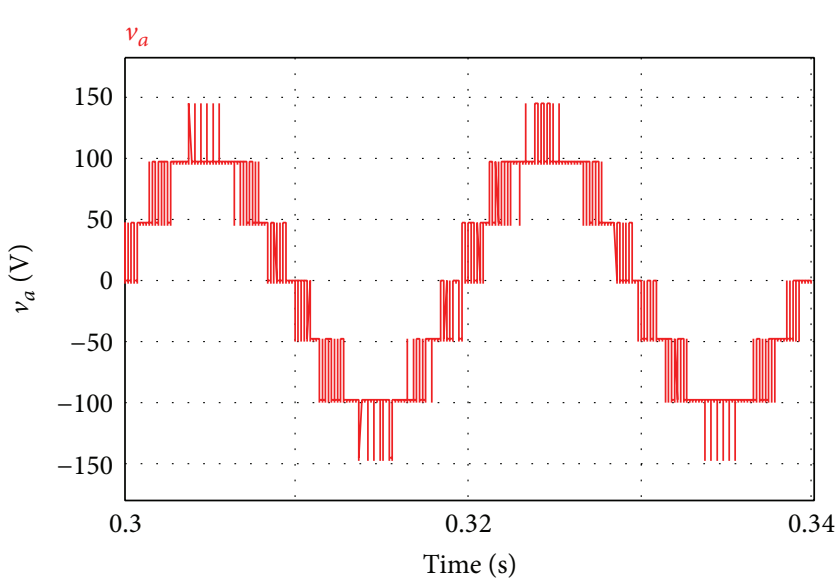

(b)

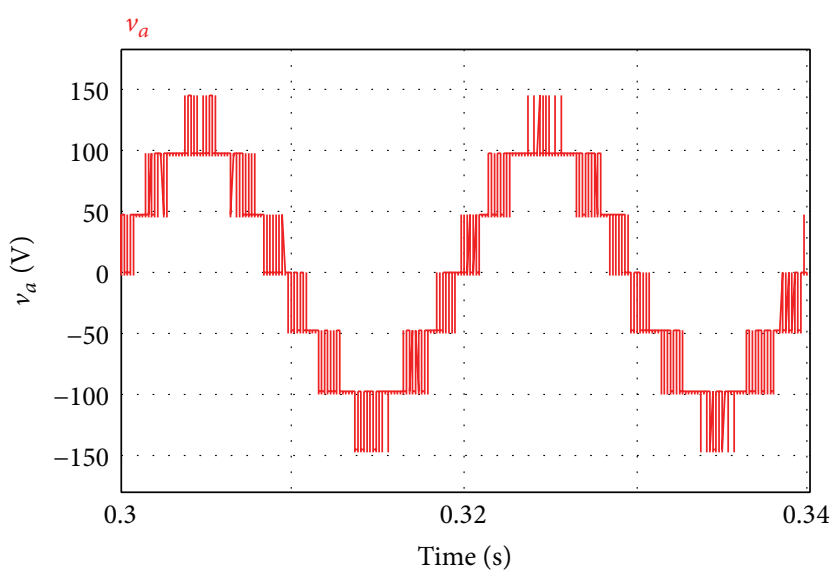

(d)

FIGURE 5: Simulation results in steady state: (a) Grid-connected current and reference current with conventional FS-MPC. (b) Output voltage with conventional FS-MPC. (c) Grid-connected current and reference current with simplified FS-MPC. (d) Output voltage with simplified FS-MPC.

(5) Predict all possible grid-connected current values of the time $k+2$ according to (10).

(6) According to the cost function of (8) to evaluate all of the predicted current value of the time $k+2$ and select the one that minimizes the cost function as the optimal value, the switch state corresponding to the optimal value is the optimal switch state.

(7) Wait until sampling time $k+1$ and turn back to step (1).

\section{Simulation and Experimental Results}

5.1. Simulation Result. Simulations of a single-phase threecell CHB grid-connected inverter were carried out using PSIM9.1.1. The simulation results of the conventional FSMPC control strategy and the simplified FS-MPC control strategy are presented. The conventional FS-MPC uses the switching states shown in Table 1 to predict grid-connected
TABLE 2: System parameters.

\begin{tabular}{lc}
\hline System parameters & Value \\
\hline DC voltage of CHB inverter $V_{\mathrm{dc}}$ & $48 \mathrm{~V}$ \\
Grid voltage $e_{\mathrm{RMS}}$ & $70.7 \mathrm{~V}$ \\
Filter inductance $L$ & $8.2 \mathrm{mH}$ \\
Inductance equivalent resistance $R$ & $0.5 \Omega$ \\
Sample time $T_{\mathrm{s}}$ & $100 \mu \mathrm{s}$ \\
Frequency of reference current $f$ & $50 \mathrm{~Hz}$ \\
\hline
\end{tabular}

current and does not consider two-step FS-MPC and adjacent levels. System parameters are shown in Table 2.

Steady waveforms are shown in Figure 5. It can be observed that the output voltage of both methods is of seven levels, and the grid-connected current of both methods can track reference current accurately. The reference current has the same frequency and phase with the grid voltage. Amplitude of the reference current is $5 \mathrm{~A}$. 


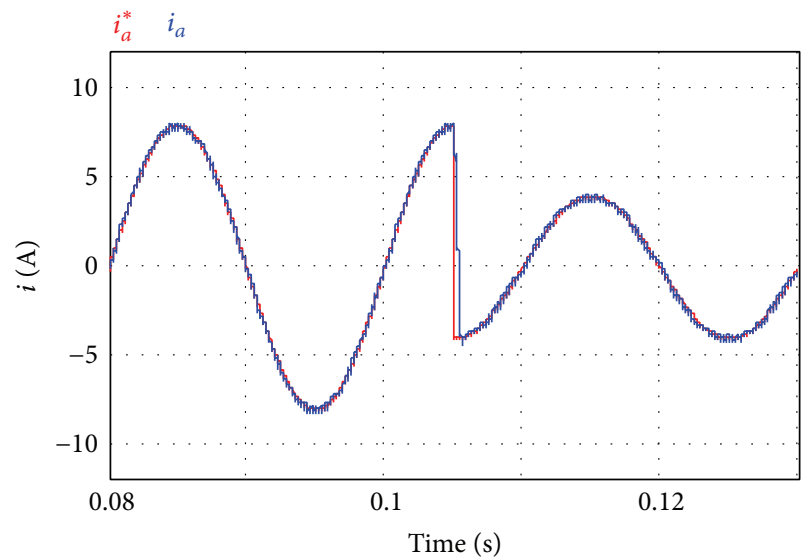

(a)

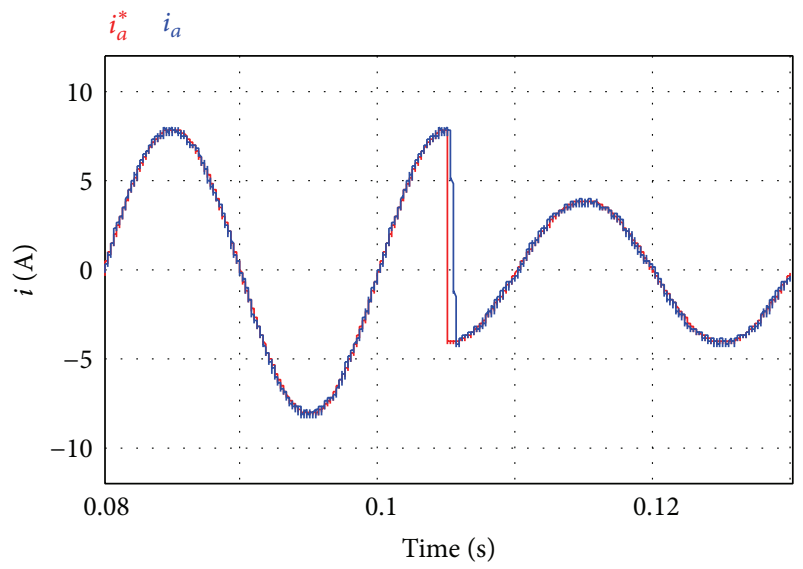

(c)

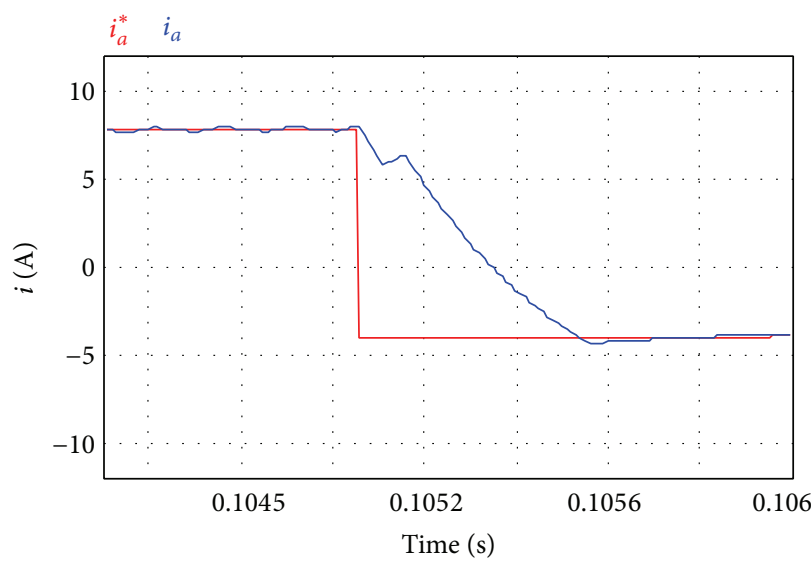

(b)

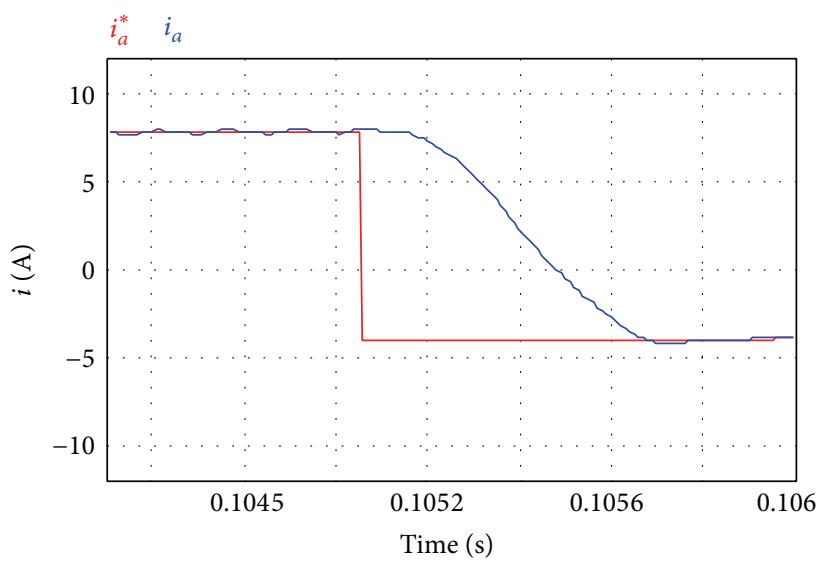

(d)

FIGURE 6: Grid-connected current for a step change in the reference amplitude. (a) Grid-connected current with conventional FS-MPC. (b) Detail of the reference step change showing the grid-connected current with conventional FS-MPC. (c) Grid-connected current with simplified FS-MPC. (d) Detail of the reference step change showing the grid-connected current with simplified FS-MPC.

The current step responses of conventional FS-MPC and simplified FS-MPC are shown in Figure 6. The current reference steps from $8 \mathrm{~A}$ to $4 \mathrm{~A}$ in amplitude and $0^{\circ}$ to $180^{\circ}$ in phase.

In Figures 6(b) and 6(d), it can be observed that the difference of current response time is about $150 \mu$ s comparing the simplified FS-MPC and conventional FS-MPC. It also can be observed in Figure 7 that when using simplified FS-MPC, the step change of output voltage response is slower than the case of using conventional FS-MPC. This change is because the selection of adjacent levels does not allow for big changes in the output voltage. When all levels are considered, it is possible to generate extreme voltage changes. On the contrast, when only adjacent levels are considered, voltage changes are limited to one level during each sampling time. The dynamic performance considering adjacent level is similar to another, but a voltage waveform with smaller $d v / d t$ can be obtained.

5.2. Experimental Results. Experiment of a single-phase three-cell $\mathrm{CHB}$ grid-connected inverter was carried out.
The predictive control algorithm was implemented in a TMS320F28335 DSP. The experimental parameters are the same as the simulation parameters, as shown in Table 2. Here, experimental results are compared with simulation results, obtaining very similar performance.

Steady waveforms are shown in Figure 8. It can be observed in Figures $8(\mathrm{~b})$ and $8(\mathrm{~d})$ that the output voltage of both methods is of seven levels, and the grid-connected current lags behind the output voltage because of the influence of the inductor. The grid-connected current has the same frequency and phase with the grid voltage, as shown in Figures 8(a) and 8(c). And the steady-state waveforms of the proposed converter are shown in Figure 9(a). The collector-emitter voltage waveforms for one IGBT of each cell are shown in Figure 9(b), which show the asymmetry in the commutation of power semiconductor devices.

Considering the first 50 harmonics, THD of the gridconnected current with conventional FS-MPC and simplified FS-MPC is shown in Figure 10. It can be seen that the THD of the grid-connected current with conventional FS-MPC is 


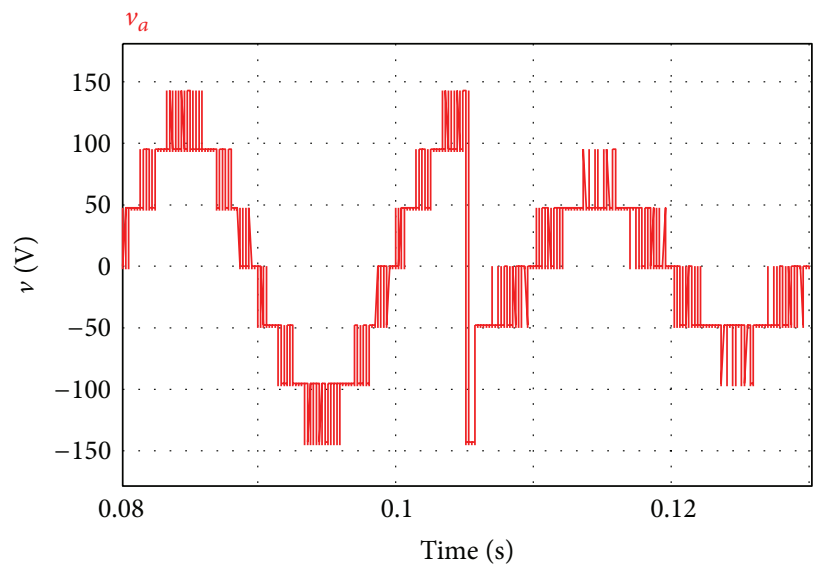

(a)

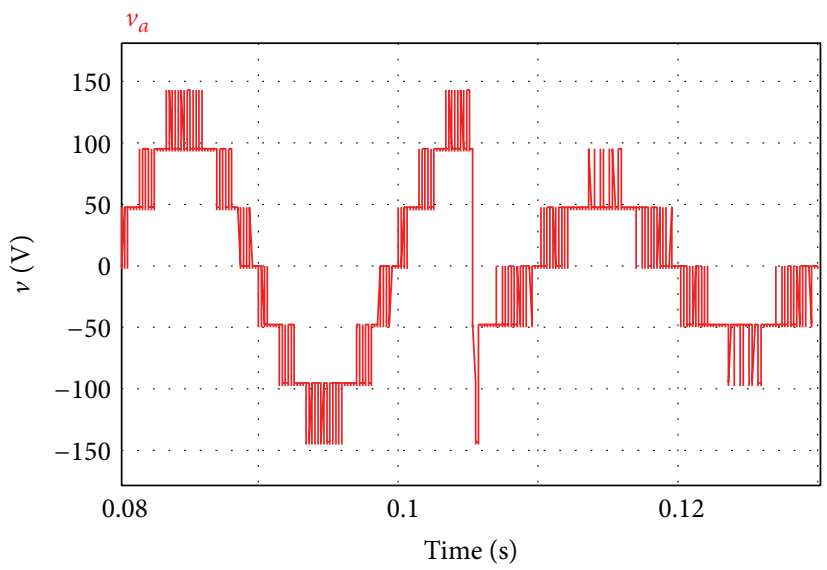

(c)

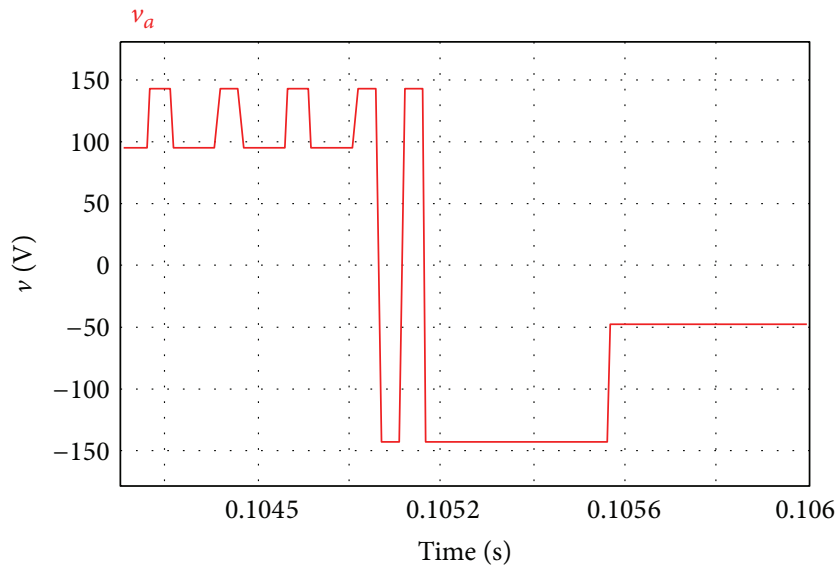

(b)

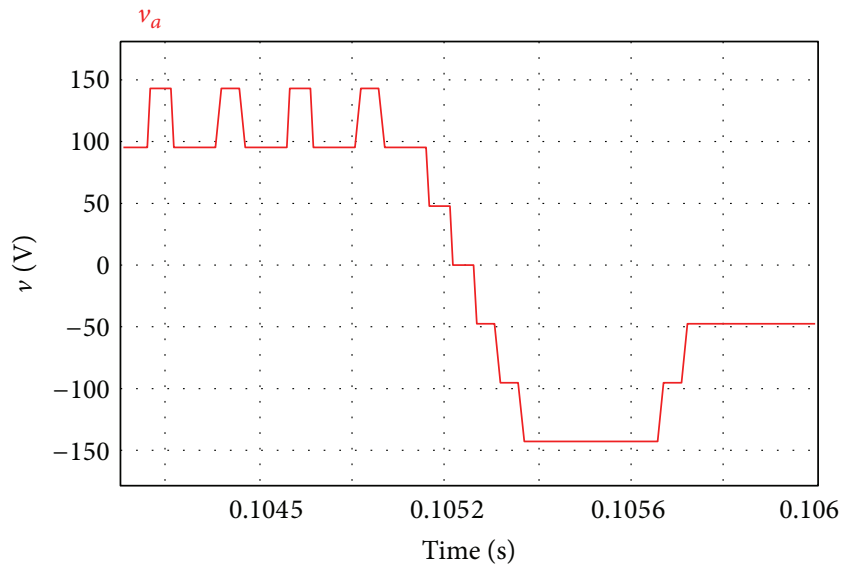

(d)

FIGURE 7: Output voltage for a step change in the reference amplitude. (a) Output voltage with conventional FS-MPC. (b) Detail of the reference step change showing the output voltage with conventional FS-MPC. (c) Output voltage with simplified FS-MPC. (d) Detail of the reference step change showing the output voltage with simplified FS-MPC.

$3.06 \%$, while the THD of the grid-connected current with conventional FS-MPC is $2.45 \%$. It illustrates that, compared with the conventional FS-MPC strategy, the inverter has better grid-connected current steady-state performance with the simplified FS-MPC control strategy.

The current and voltage step responses of conventional FS-MPC and simplified FS-MPC are shown in Figure 11. The current reference steps from $8 \mathrm{~A}$ to $4 \mathrm{~A}$ in amplitude and $0^{\circ}$ to $180^{\circ}$ in phase.

It can be observed, in the detailed view of the step change instant, shown in Figures 11(b) and 11(d), that the dynamic adjustment ability of simplified FS-MPC to grid-connected current is slightly lower than that of conventional FS-MPC, but the difference between them is not significant. It also can be observed that the output voltage of conventional FSMPC changes sharply when the amplitude of the reference current changes. The sharp change will reduce the stability of the system and the service life of power switch devices. But when using simplified FS-MPC, the step change of output voltage response is slower than the case of using conventional
FS-MPC. This is the same as the simulation results. In summary, on the one hand, simplified FS-MPC improved grid-connected current steady-state performance; on the other hand, it reduced the rate of change of the output voltage.

\section{Conclusions}

The problem of the delay due to the calculation time in conventional FS-MPC method has been explained in this paper, and a simplified FS-MPC method has been presented. The simplified FS-MPC method is verified with simulation and experimental results. Using this method, the THD of the gridconnected current and $d v / d t$ are considerably reduced. The simplified FS-MPC method can be applied to any multilevel inverter with a high number of levels and switching states.

\section{Competing Interests}

The authors declare that they have no competing interests. 


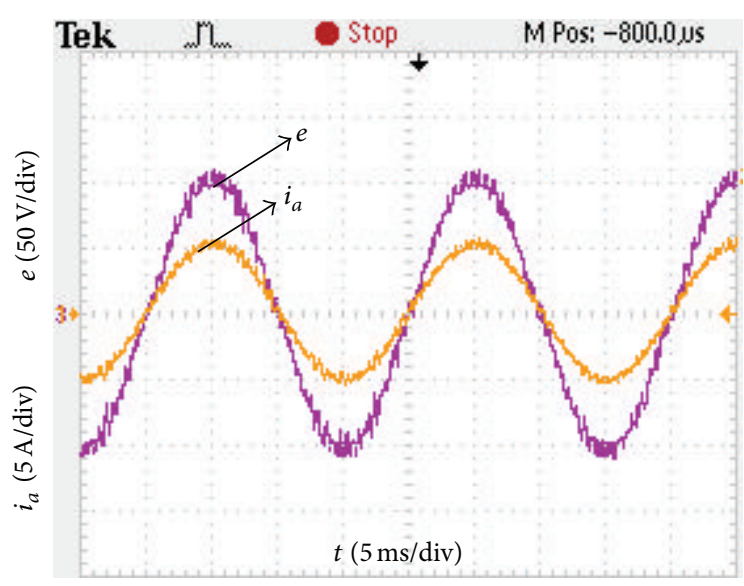

(a)

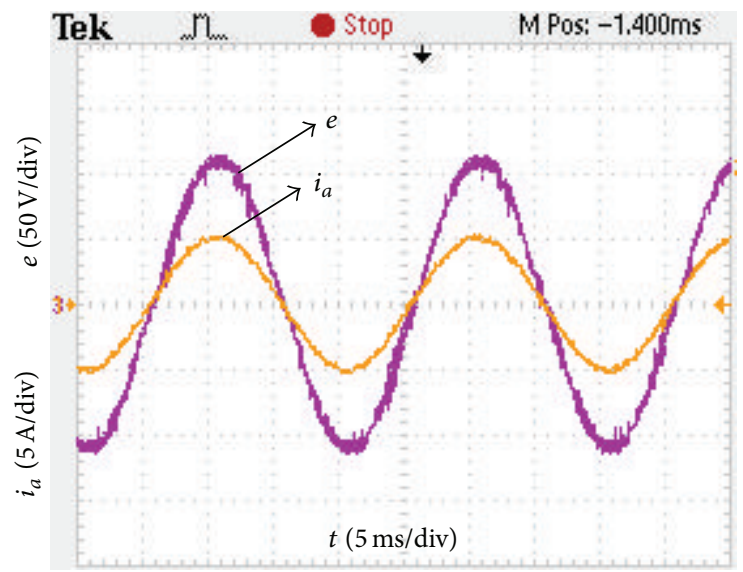

(c)

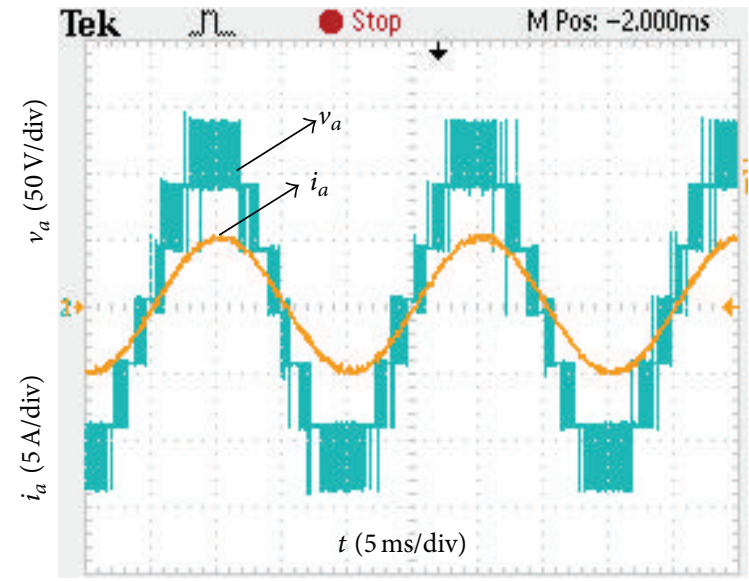

(b)

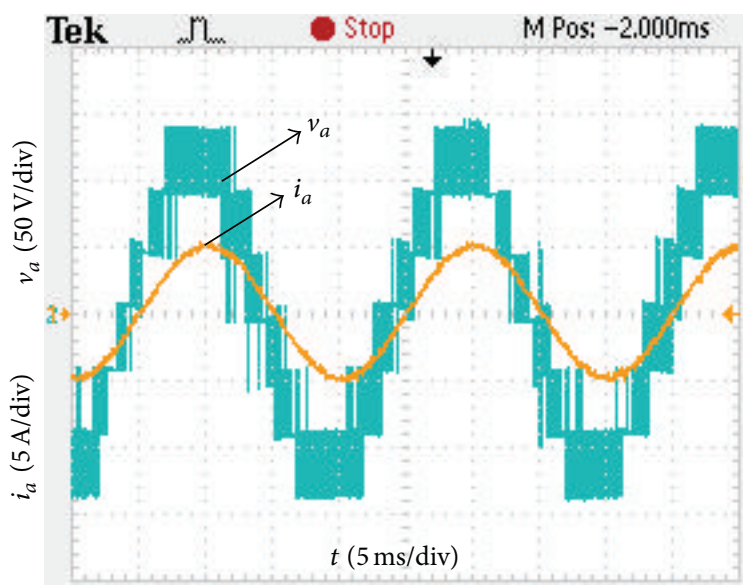

(d)

FIGURE 8: Experimental results in steady state: (a) Grid-connected current and grid voltage with conventional FS-MPC. (b) Output voltage and grid-connected current with conventional FS-MPC. (c) Grid-connected current and grid voltage with simplified FS-MPC. (d) Output voltage and grid-connected current with simplified FS-MPC.

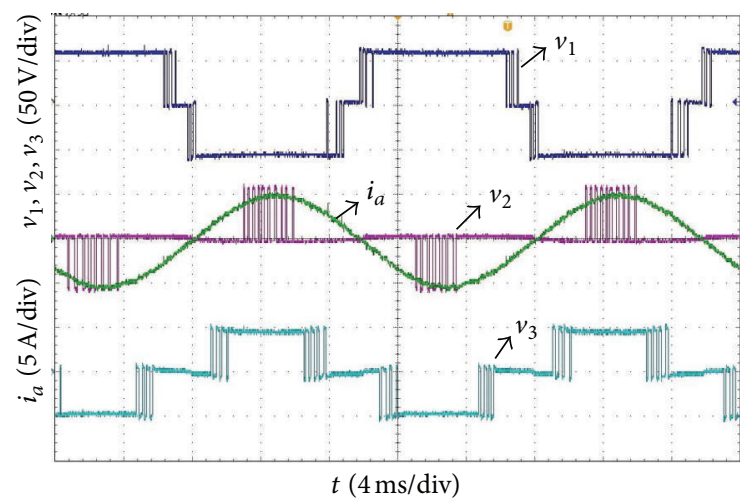

(a)

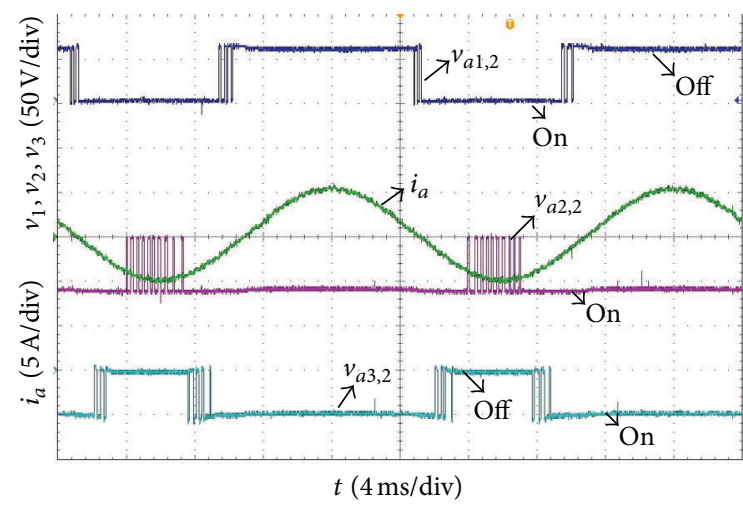

(b)

FIGURE 9: Waveforms of the converter with simplified FS-MPC: (a) Output voltage of each cell. (b) The collector-emitter voltage waveforms for one IGBT of each cell (the upper IGBT of right leg). 


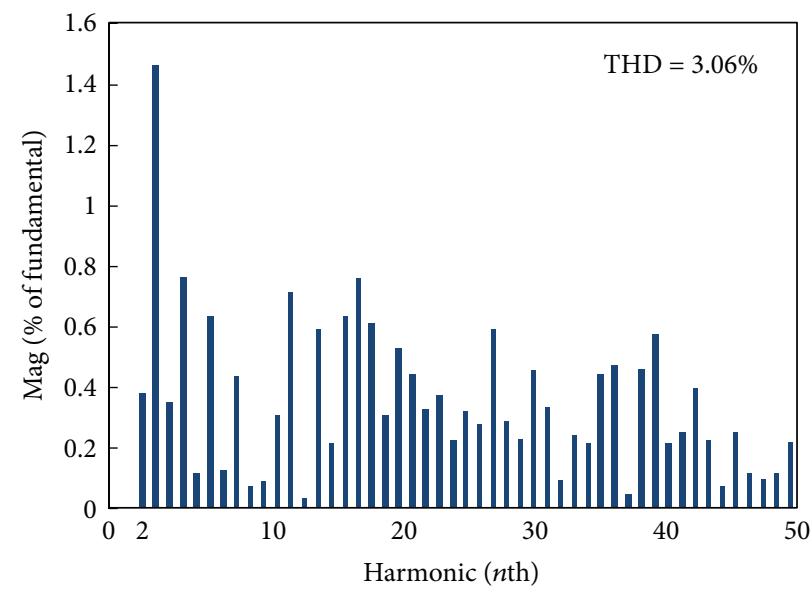

(a)

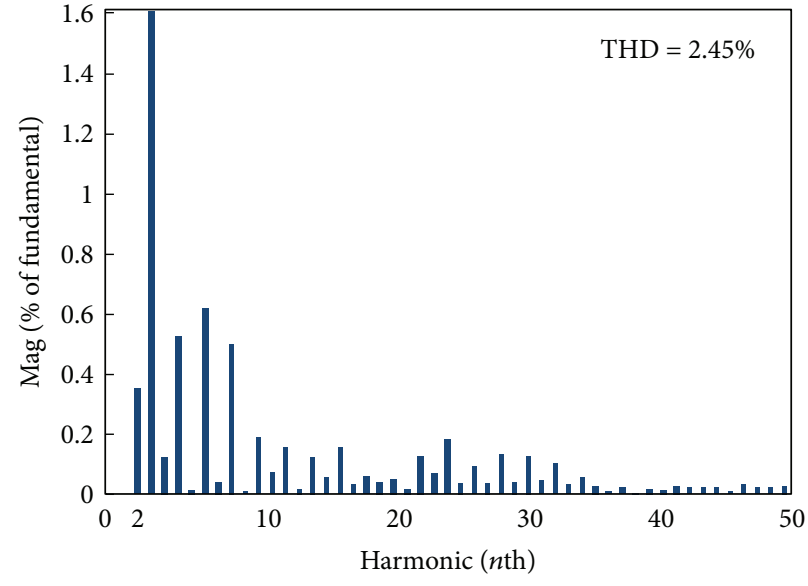

(b)

FIGURE 10: THD of grid-connected current: (a) THD of the grid-connected current with conventional FS-MPC. (b) THD of the gridconnected current with simplified FS-MPC.

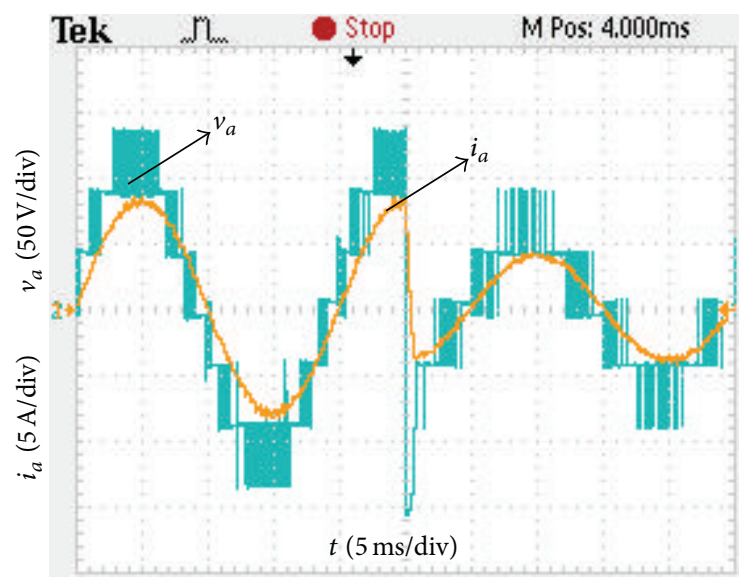

(a)

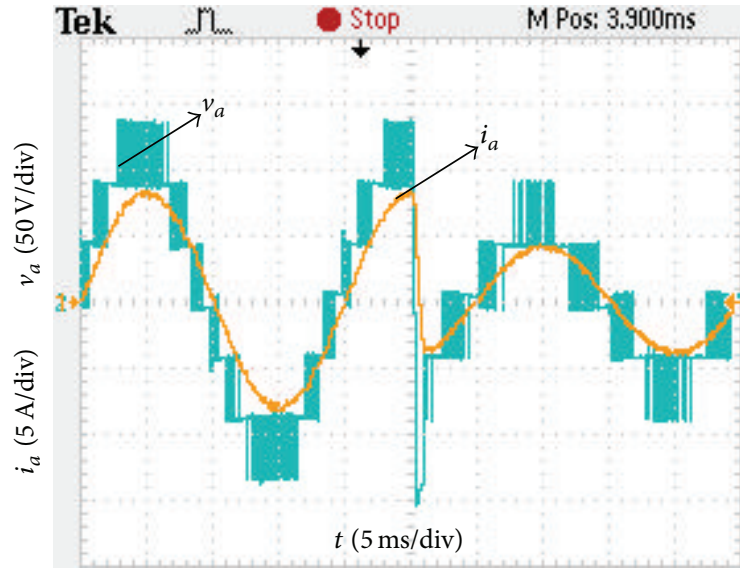

(c)

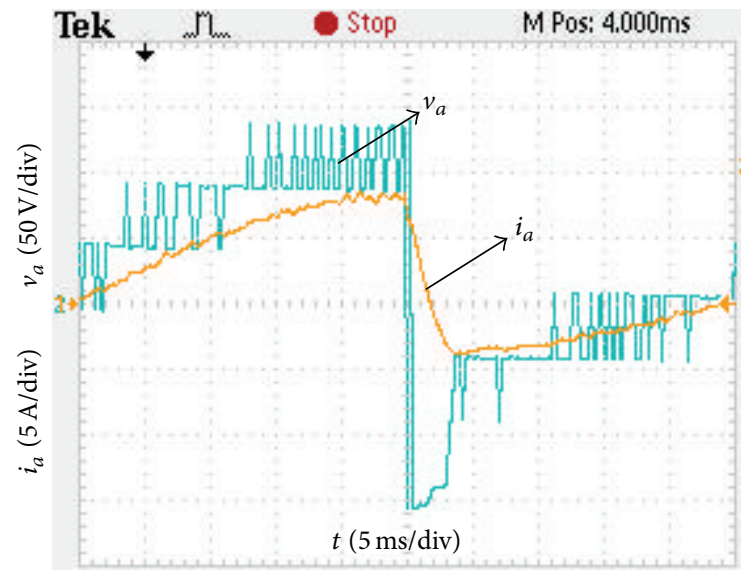

(b)

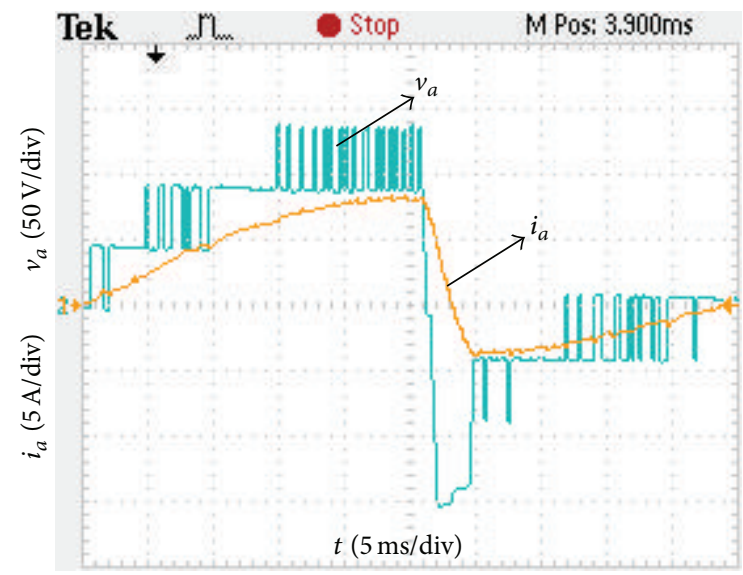

(d)

FIGURE 11: Grid-connected current and output voltage for a step change in the reference amplitude. (a) Grid-connected current and output voltage with conventional FS-MPC. (b) Detail of the reference step change showing the grid-connected current and output voltage with conventional FS-MPC. (c) Grid-connected current and output voltage with simplified FS-MPC. (d) Detail of the reference step change showing the grid-connected current and output voltage with simplified FS-MPC. 


\section{Acknowledgments}

This work was partly supported by Shanghai Municipal Natural Science Foundation under Grant no. 15ZR1419800.

\section{References}

[1] G.-J. Su, "Multilevel DC-link inverter," IEEE Transactions on Industry Applications, vol. 41, no. 3, pp. 848-854, 2005.

[2] M. Nilkar, E. Babaei, and M. Sabahi, "A new single-phase cascade multilevel inverter topology using four-level cells," in Proceedings of the 20th Iranian Conference on Electrical Engineering (ICEE '12), pp. 348-353, Tehran, Iran, May 2012.

[3] J. Pereda and J. Dixon, "Cascaded multilevel converters: optimal asymmetries and floating capacitor control," IEEE Transactions on Industrial Electronics, vol. 60, no. 11, pp. 4784-4793, 2013.

[4] A. Nabae, I. Takahashi, and H. Akagi, "A new neutral-pointclamped PWM inverter," IEEE Transactions on Industry Applications, vol. 17, no. 5, pp. 518-523, 1981.

[5] T. A. Meynard and H. Foch, "Multi-level choppers for high voltage applications," EPE Journal, vol. 2, no. 1, pp. 45-50, 1992.

[6] L. G. Franquelo, J. Rodriguez, J. I. Leon, S. Kouro, R. Portillo, and M. A. M. Prats, "The age of multilevel converters arrives," IEEE Industrial Electronics Magazine, vol. 2, no. 2, pp. 28-39, 2008.

[7] C. Attaianese, M. Di Monaco, and G. Tomasso, "High performance digital hysteresis control for single source cascaded inverters," IEEE Transactions on Industrial Informatics, vol. 9, no. 2, pp. 620-629, 2013.

[8] O. Kükrer, "Deadbeat control of a three-phase inverter with an output LC filter," IEEE Transactions on Power Electronics, vol. 11, no. 1, pp. 16-23, 1996.

[9] M. Hojabri, A. Z. Ahmad, A. Toudeshki, and M. Soheilirad, "An overview on current control techniques for grid connected renewable energy systems," in Proceedings of the 2nd International Conference on Power and Energy Systems, pp. 119-126, Pune, India, 2012.

[10] B. S. Riar, T. Geyer, and U. K. Madawala, "Model predictive direct current control of modular multilevel converters: modeling, analysis, and experimental evaluation," IEEE Transactions on Power Electronics, vol. 30, no. 1, pp. 431-439, 2015.

[11] P. Cortés, M. P. Kazmierkowski, R. M. Kennel, D. E. Quevedo, and J. Rodriguez, "Predictive control in power electronics and drives," IEEE Transactions on Industrial Electronics, vol. 55, no. 12, pp. 4312-4324, 2008.

[12] J. Rodriguez, P. Cortes, R. Kennel, and M. P. Kazmierkowski, "Model predictive control-a simple and powerful method to control power converters," in Proceedings of the IEEE 6th International Power Electronics and Motion Control Conference (IPEMC '09), pp. 41-49, Wuhan, China, May 2009.

[13] R. Vargas, P. Cortés, U. Ammann, J. Rodríguez, and J. Pontt, "Predictive control of a three-phase neutral-point-clamped inverter," IEEE Transactions on Industrial Electronics, vol. 54, no. 5, pp. 2697-2705, 2007.

[14] P. Lezana, R. Aguilera, and D. E. Quevedo, "Model predictive control of an asymmetric flying capacitor converter," IEEE Transactions on Industrial Electronics, vol. 56, no. 6, pp. 18391846, 2009.

[15] M. A. Perez, P. Cortes, and J. Rodríguez, "Predictive control algorithm technique for multilevel asymmetric cascaded $\mathrm{H}-$ bridge inverters," IEEE Transactions on Industrial Electronics, vol. 55, no. 12, pp. 4354-4361, 2008.
[16] M. Vasquez, J. Pontt, and J. Vargas, "Predictive control of a hybrid asymmetric multilevel converter with floating cells," in Proceedings of the IEEE International Conference on Industrial Technology (ICIT '14), pp. 278-283, Busan, Republic of Korea, March 2014.

[17] J. Rodríguez, J. Pont, C. A. Silva et al., "Predictive current control of a voltage source inverter," IEEE Transactions on Industrial Electronics, vol. 54, no. 1, pp. 495-503, 2007.

[18] J. Han, M. Zhao, D. Peng, and T. Tang, "Improved model predictive current control of cascaded H-bridge multilevel converter," in Proceedings of the IEEE 22nd International Symposium on Industrial Electronics (ISIE '13), pp. 1-5, IEEE, Taipei, Taiwan, May 2013.

[19] P. Cortes, J. Rodriguez, C. Silva, and A. Flores, "Delay compensation in model predictive current control of a three-phase inverter," IEEE Transactions on Industrial Electronics, vol. 59, no. 2, pp. 1323-1325, 2012. 


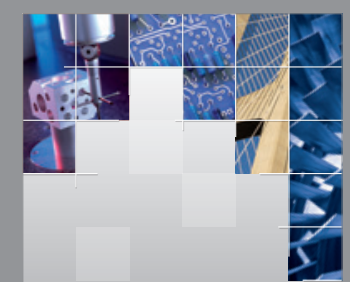

\section{Enfincering}
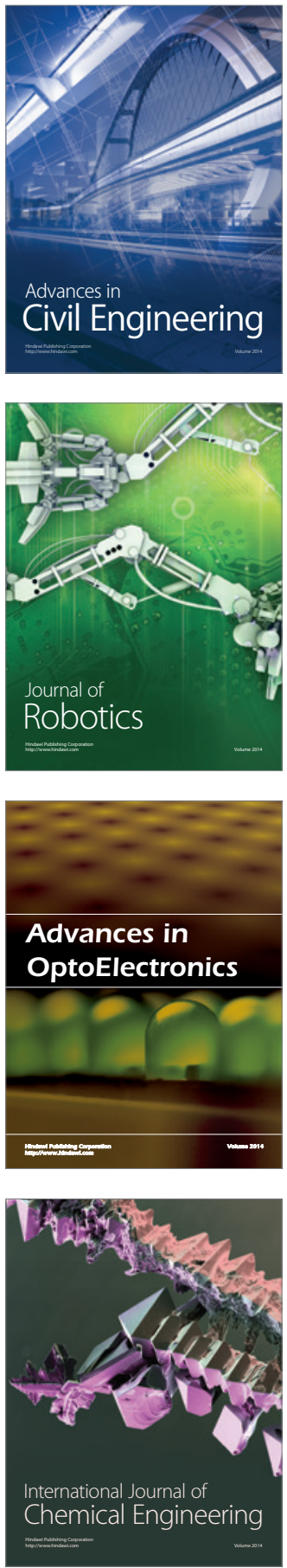

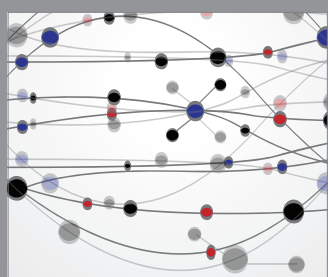

The Scientific World Journal

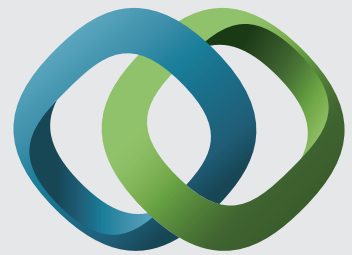

\section{Hindawi}

Submit your manuscripts at

http://www.hindawi.com
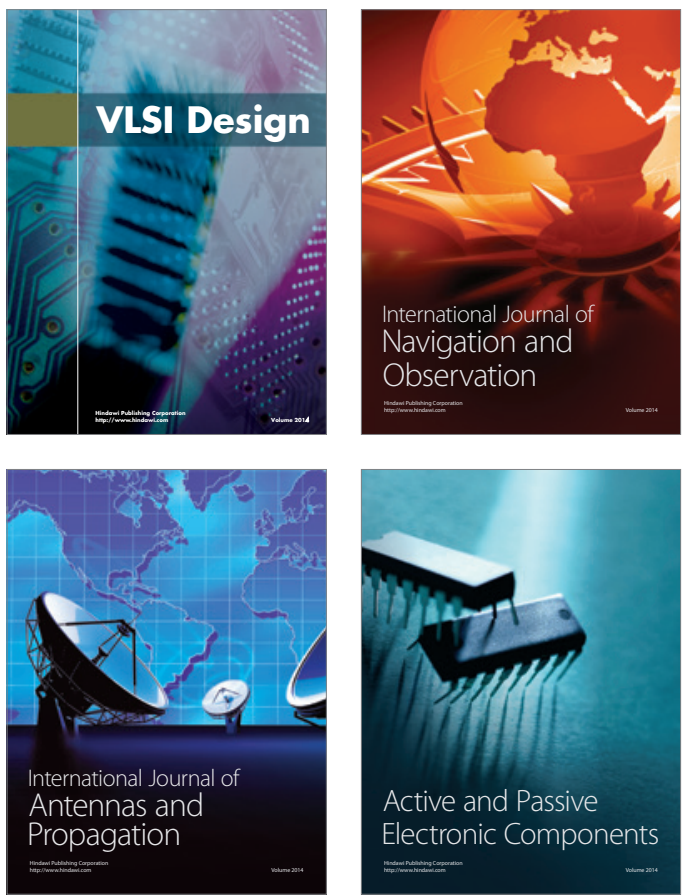
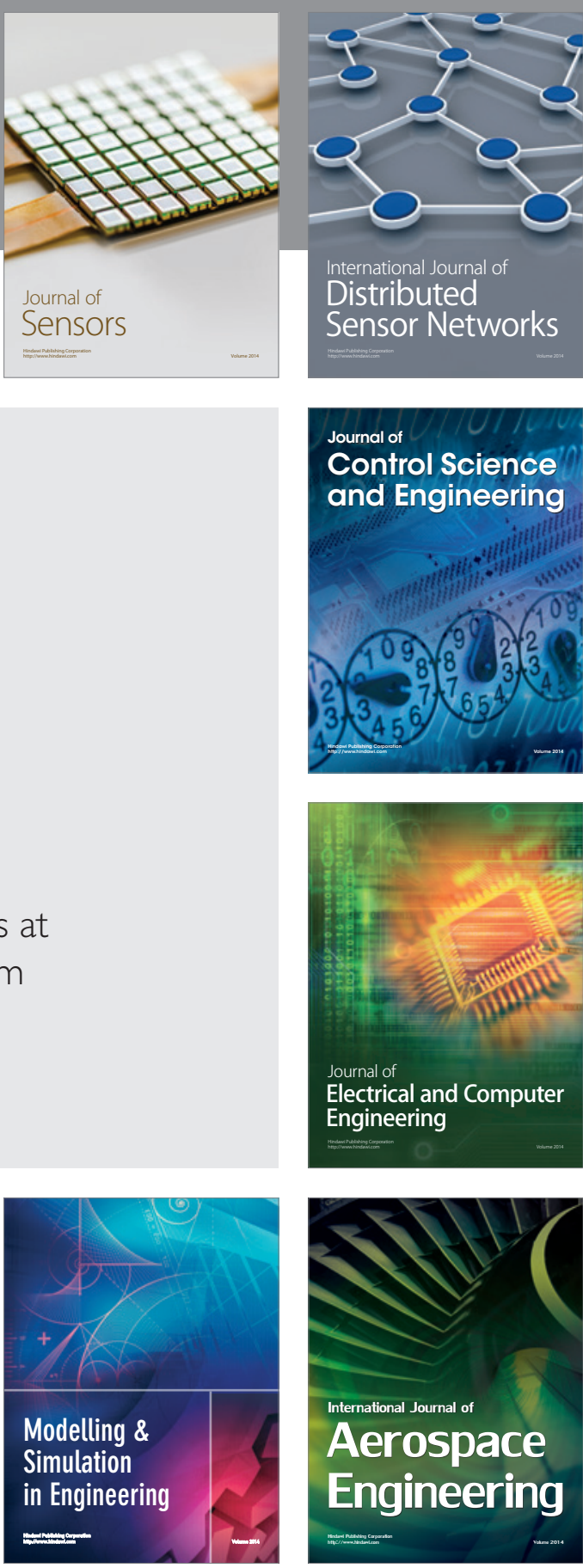

International Journal of

Distributed

Sensor Networks

Journal of

Control Science

and Engineering
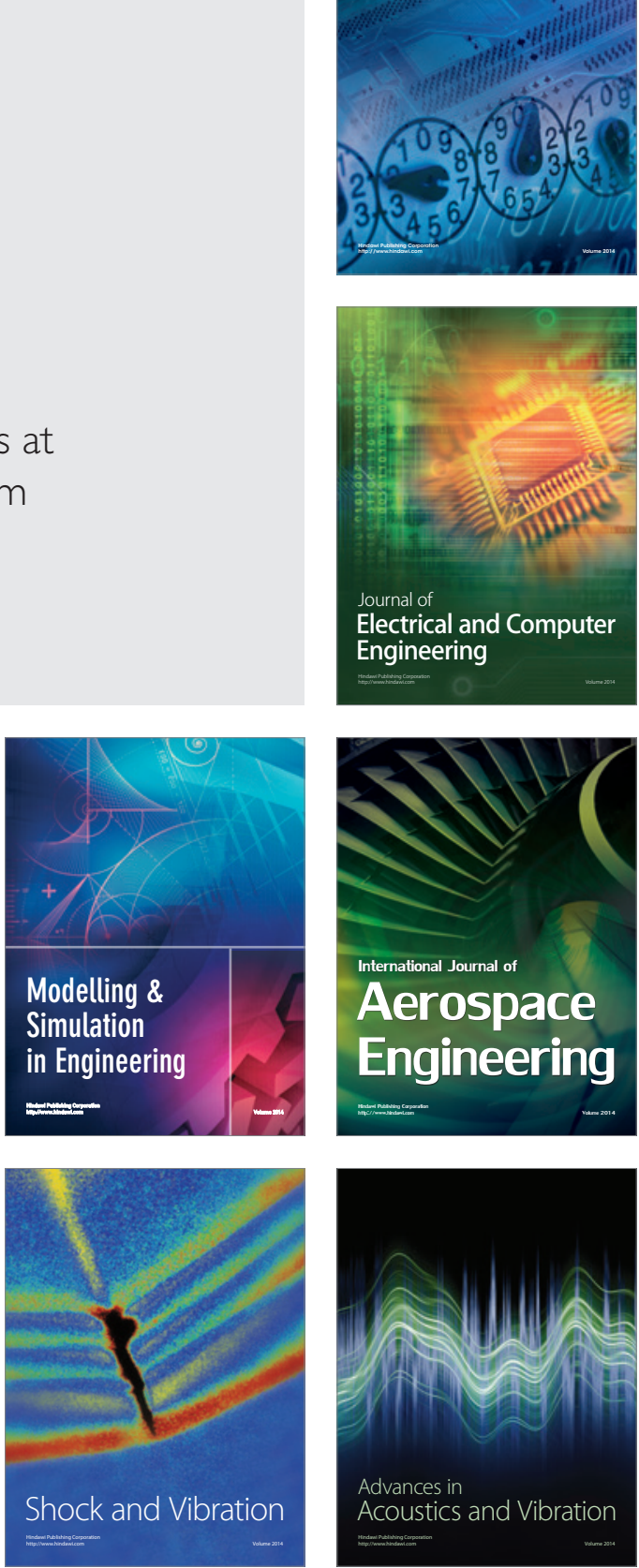